\title{
TABLE DES ILLUSTRATIONS
}

\section{ET RENVOIS AU TEXTE.}

\section{Planches.}

Pl. I. - Plan d'Ańkor Thom; échelle : I/25.000; p. I.

Le coté d'un carré en pointillé représente 200 mètres.

Pl. II. - Monument 486. Plan; échelle: o m. or p. m.; p. 2.

Le cordon de pourtour en latérite passe à $10 \mathrm{~m}$. 50 à l'Est de la terrasse orientale et à $3 \mathrm{~m}$. 40 des perrons $\mathrm{S}$., $\mathrm{O}$. et $\mathrm{N}$.

PI. III. - Monument 486. Sanctuare central. face E., p. 2.

Pl. Iv. - Monument 486. Détails : $A$, linteau O., p. 3 ; $B$, linteau S., p. 3.

Pl. v. - Monument 487. Face E., p. 6.

Pl. vi. - Monument 487. Face S., p. 6.

Pl. vil. - Monument 487. Fragments de frontons; $A$, p. $7 ; B$, p. 7 .

Pl. vill. - Monument 487. Borne sculptée, p. 7.

Pl. ix. - Terrasse bouddhique No I. Plan; ćchelle: o m. 002 p. m.; p. 12 ; - détails; échelle : o m. 025 p. m. ; p. 9.

PI. $\mathrm{x}$. - Terrasses bouddhiques nos 2 et 4. En haut de la planche: Terrasse n" 2 , plan d'ensemble; échelle: om. 002 p. m.; - coupes; échelle: o m.01 p.m.; p. 14. En bas de la planche: Terrasse no 4. Plan; échelle: om. 002 p. m. ; p. 16.

Pl. xi. - Pièces truuvées en divers points. Echelles diverses.

$A$. mortier à riz (terrasse $(O)$, p. 35. - B, dalle (terrasse $O$ ), p. 35. C. statuette (terrasse no 5), p. 18. - D, statuette (terrasse $L$ ), p. 30. $E$, bas-relief (terrasse $M$ ) , p. 31 . - F. petit vase en terre cuite (terrasse no 3 ), p. 16. - G, statue (terrasse $D$ ). p. 26. - $H$, tête (édicule $N$ ), p. 33. $-I$, tuile en terre cuite (terrasse $L$ ), p. 30 . $-J$, borne (terrasse $L$ ), p. $30 .-K$, tuile en terre cuite émaillée (terrasse no 5 ), p. 18. $-L$, stèle (édicule $N$ ), p. 33.

Les pièces dont la matière n'est pas indiquée sont en grès.

PI. xiI. - Terrasse D. Fronton reconstitué, p. 26.

Le couronnement, orné d'une tète dans la feuille centrale, placé sur la dernière assise complète, appartient $a \dot{u} u$ autre fronton.

XVIII, 8 